\title{
Role of radiotherapy in the treatment of metastatic head and neck cancer
}

This article was published in the following Dove Medical Press journal: OncoTargets and Therapy

\section{Rafael Ordoñez \\ Ana Otero \\ Inmaculada Jerez \\ Jose A Medina \\ Yolanda Lupiañez-Pérez \\ Jaime Gomez-Millan}

Department of Radiation Oncology, Hospital Universitario Virgen de la

Victoria, Málaga, Spain
Correspondence: Jaime Gomez-Millan Department of Radiation Oncology, Hospital Universitario Virgen de la Victoria, Campus Teatinos, SN. 290I0, Málaga Spain

Tel +3495 1032617

Fax +34 $95 \quad 10326 I 5$

Email jaimegomezmillan@gmail.com

\begin{abstract}
In metastatic or locally advanced head and neck tumors that present in frail patients or after chemotherapy progression, radiotherapy is normally used as a palliative treatment, with a high rate of symptom palliation and improvement in quality of life. However, there is controversy about what the optimal regimen is. Moreover, despite the poor prognosis of metastatic head and neck cancer, different retrospective studies have shown that a minority of patients with oligometastatic disease experience prolonged disease-free survival after adding curative radiotherapy treatment to the metastatic disease and/or primary tumor. Different retrospective studies have identified clinical prognostic factors that may be used to select candidate patients with metastatic head and neck cancer for a radical approach with radiotherapy. The purpose of this manuscript is to review the role of radiotherapy in metastatic and locally advanced head and neck tumors.
\end{abstract}

Keywords: palliative, head and neck cancer, radiotherapy, oligometastatic disease

\section{Introduction}

Head and neck cancer (HNC) has a predominant locoregional pattern of recurrence, with local and/or regional recurrence rates of $45 \%-50 \%$ and incidence of distant metastasis $(\mathrm{DM})<20 \% .{ }^{1}$ However, in cases with advanced lymphatic cervical disease, such as N3 cases or when lower cervical nodes are affected, DM incidence may rise to approximately $30 \%{ }^{2}$ Cetuximab has been shown to prolong overall survival (OS) in patients with advanced or metastatic $\mathrm{HNC}$ ( $\mathrm{mHNC}$ ) who have received chemotherapy (from 7.4 months to 10.1 months, $P=0.04$ ) and is actually considered the first line palliative systemic treatment in this disease. ${ }^{3}$ On the other hand, radiotherapy (RT) has been used as palliative treatment in this clinical setting, with a high rate of symptom palliation and improvement in quality of life for patients presenting progression after chemotherapy or in frail patients who are not candidates for chemotherapy. ${ }^{4}$

Despite the poor prognosis of $\mathrm{mHNC}$, different retrospective studies have shown that a minority of patients with oligometastatic disease experience prolonged diseasefree survival after the addition of curative RT treatment to the metastatic disease and/or primary tumor. Moreover, technological and clinical advances achieved in the field of RT have improved the balance between tumor control and effects on normal tissue, increasing the therapeutic ratio. ${ }^{5}$ As a result, indications for RT have expanded in recent years to include patients that would not have been treated a few years ago. The purpose of this manuscript is to review the role of RT in patients with $\mathrm{mHNC}$, and to study the prognostic factors that should be identified to select patients with mHNC who are suitable candidates for a more radical approach. 


\section{Methods}

A search for the published results of stereotactic body RT or external RT for mHNC was carried out using Medline, Embase, and Ovid Online via the Athens website. Terms searched for (all fields) were "stereotactic radiosurgery", "stereotactic body radiotherapy", "stereotactic body radiation therapy", "head and neck neoplasm", "metastases", and "oligometastases". Appropriate manuscripts were selected from the lists generated, and additional papers found through a manual search of the references contained in these publications were added. The period of inclusion was 2007-2018.

\section{Results}

\section{Metastatic disease in head and neck cancer}

The combination of cetuximab with chemotherapy has traditionally been considered standard treatment for these patients. ${ }^{4}$ However, in patients that progress after chemotherapy or in frail patients, RT has been used as a palliative treatment, with a high rate of symptom palliation and an improvement in quality of life.

There is no consensus on the most appropriate treatment scheme. To increase patient comfort, reducing the number of hospital visits and shorter regimens using low biological doses have been tested. Mohanti et al (AIIMS study) proposed a five-fraction course of treatment to a total dose of up to $20 \mathrm{~Gy}$, showing modest tumor response (37\%) and symptom relief (47\%-59\%). ${ }^{6}$ Fortin et al recently performed a phase II study with a dose of 25 Gy in five fractions administered with intensity-modulated RT. Although treatment response was not reported, self-reported outcomes showed that $85 \%$ of patients were satisfied with the treatment, and it had a toxicity as low as $13 \%$ grade III toxicity, with no grade IV-V toxicity reported. ${ }^{7}$

The association between a higher biological dose and an increase in tumor response and survival shown in different studies $^{8}$ has led to the investigation of longer RT schemes with higher doses of radiation (Table 1). Stevens et al performed a retrospective multivariate analysis in a cohort of patients treated with several fractional regimens. One of the most commonly used was a split course composed of two cycles of 25 Gy in ten fractions given within 2 weeks, separated by a 2-week break to a total dose of 50 Gy. Treatment response was $82 \%$, while $85 \%$ of patients had an improvement in their symptoms. ${ }^{8}$ Corry et al published the results of "The Quad Shot regimen", that consisted of three courses of twice-daily 3.7 Gy fractions for two consecutive days, completing a total dose of 44.4 Gy in twelve fractions over 8-9 weeks. An overall palliation rate of $80 \%$ was reported, with a tumor-response rate of 50\%-70\%. ${ }^{9}$ Porceddu et al used higher doses per fraction, delivering 30-36 Gy in five to six twice-weekly fractions of $6 \mathrm{~Gy}$. An objective response of $80 \%$ was achieved, and $62 \%$ patients reported an overall improvement in quality of life. Treatment tolerance was high, with $88 \%$ of patients receiving $\geq 30$ Gy. However, $26 \%$ of patients experienced $\mathrm{G} 3$ mucositis, and $11 \%$ reported severe dysphagia. ${ }^{4}$ Finally, Agarwal et al described a treatment response of $73 \%$ and $>75 \%$ symptomatic relief with a palliative RT-alone regimen delivering $40 \mathrm{~Gy}$ in 16 fractions. It should be noted that G3 mucositis was described in $26 \%$ of the patients, and $11 \%$ required nutritional support with a gastric tube. ${ }^{10}$

Therefore, in patients with better performance status (PS; 0-2), a palliative regimen using a higher biological dose may be indicated, provided that when selecting patients consideration is given to the fact that a significant number may experiment high mucosal toxicity ( $>$ G2). On the other hand, among patients with suboptimal PS $(>2)$ or short survival expectancy, a palliative regimen with a low dose is indicated. An algorithm for RT in mHNC is described in Figure 1.

\section{Oligometastatic disease in head and neck cancer}

Oligometastatic disease is a term coined by Hellman and Weichselbaum ${ }^{11}$ that describes a less advanced state of metastatic disease that may produce a limited number of metastases over long periods of time, amenable to potential

Table I Studies with palliative radiotherapy

\begin{tabular}{|c|c|c|c|c|}
\hline Study & Design & Patients & Treatment & Results \\
\hline Mohanti et $\mathrm{al}^{6}$ & Retrospective & Advanced HNC & $20 \mathrm{~Gy} / 5 \mathrm{~Gy} / 4$ days & ORR $37 \%$; SR 47\%-59\% \\
\hline Fortin et $\mathrm{al}^{7}$ & Phase II & Advanced HNC & $25 \mathrm{~Gy} / 5 \mathrm{~Gy} / 5$ days & $\begin{array}{l}\text { Satisfaction rate } 85 \% \text {; } \\
\text { G3 toxicity } 13 \%\end{array}$ \\
\hline Stevens et $\mathrm{al}^{8}$ & Retrospective & Advanced HNC & 25 Gy/2.5 Gy/6 weeks (split course) & ORR 82\%; SR 85\% \\
\hline Corry et $\mathrm{al}^{9}$ & Retrospective & Advanced HNC & 44.4 Gy/3.7 Gy BID/8-9 weeks & ORR $50 \%-70 \%$ \\
\hline Porceddu et $\mathrm{al}^{4}$ & Phase II & Advanced HNC & 30-36 Gy/6 Gy/3 weeks & ORR $80 \%$; G3 toxicity $26 \%$ \\
\hline Agarwal et al ${ }^{10}$ & Phase II & Advanced HNC & $40 \mathrm{~Gy} / 2.5 \mathrm{~Gy} / 3$ weeks & ORR $73 \%$; G3 toxicity $26 \%$ \\
\hline
\end{tabular}

Abbreviations: HNC, head and neck cancer; ORR, overall response rate; SR, subjective response. 


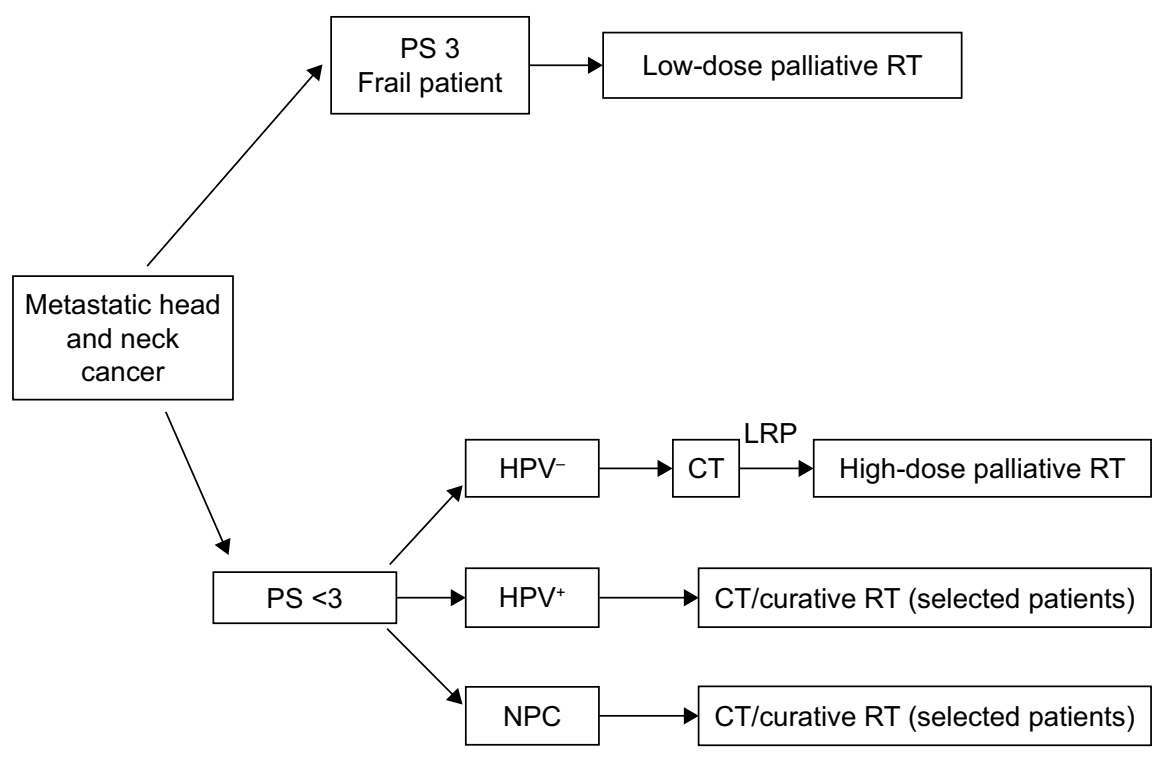

Figure I Algorithm for RT in metastatic head and neck cancer.

Abbreviations: CT, chemotherapy; HPV, human papillomavirus; LRP, locoregional progression; NPC, nasopharyngeal cancer; PS, performance status; RT, radiotherapy.

curable local therapy. ${ }^{12}$ Data point to the hypothesis that development of widespread metastases may occur because of seeding from oligometastasis after more alterations in the chromosome have been accumulated. In HNC, oligometastatic disease may present different prognoses, depending on the location, status of the primary tumor location, and tumor histology.

\section{Patients with primary tumors controlled}

It has been shown that a subset of patients with $\mathrm{mHNC}$ and favorable prognostic factors may present long survival. A recent systematic review has shown that in patients with a controlled primary tumor, metastasectomy for metachronous pulmonary metastasis may offer prolonged survival for selected patients, with an overall absolute 5-year survival rate of $29.1 \% .{ }^{13}$ Moreover, different retrospective studies of selected patients with surgically treated oligometastatic disease in the lung have shown 5-year survival rates of $30 \%-60 \%{ }^{14}$ To select which patients might benefit from this approach, different studies have shown that the presence of cervical metastases on diagnosis of the primary tumor, ${ }^{15}$ tumors located in the oral cavity, ${ }^{16}$ incomplete pulmonary resection, ${ }^{15}$ and the presence of multiple pulmonary nodules ${ }^{17}$ significantly decrease the survival-rate probability for oligometastatic disease.

Stereotactic body RT (SBRT) consists in the delivery of a high ablative dose through the application of one to five high-dose fractions. ${ }^{18} \mathrm{~A}$ high dose per fraction will deliver a higher biological effect in normal tissue with slow proliferative capacity (low $\alpha: \beta$ ratio) compared with most tumors or rapid proliferative capacity tissue (high $\alpha: \beta$ ratio). ${ }^{19}$ However, the advances in techniques and imaging accomplished in recent years have contributed to the design of treatments with higher conformation and improvement in RT precision, with reproducible immobilization, precise target localization, and tumor tracking, all of which make it possible to treat tumors with high ablative doses and low toxicity.

SBRT has been successfully tested in lung cancer and metastatic disease in the lung or liver, where the parallel structure of the lung or liver allows delivery of a high dose to a minimum volume of tissue without clinical manifestations. ${ }^{20}$ The use of SBRT for the treatment of metastasis derives from excellent results obtained in early lung cancer, improving the suboptimal results obtained in the past with external RT, in which the amount of lung tissue irradiated did not allow ablative doses of radiation to be reached.

Different nonrandomized studies have shown that SBRT is a safe and effective method to treat lung metastases derived from different tumors, obtaining similar results to surgery. Local control rates of $80 \%-85 \%$ have been described, ${ }^{21-24}$ as have 2- to 3-year progression-free survival of $20 \%$ and a predominant pattern of recurrence at a distance. ${ }^{23}$ However, most of these series did not focus exclusively on HNC, and presented a variety of metastases of different origins with a low percentage of $\mathrm{HN}$ tumors that ranged between $8 \%{ }^{23}$ and $18 \%{ }^{24}$ (Table 2). Moreover, although some authors have described better control of metastasis in HNC compared with metastasis from colorectal cancer, ${ }^{25}$ it is not possible to reach definitive conclusions, due to the low number of $\mathrm{HN}$ tumors included in the series analyzed. Similar results have been 
Table 2 Oligometastatic disease in the lung with primary tumor controlled

\begin{tabular}{|c|c|c|c|c|}
\hline Study & Design & Patients & Treatment & Results \\
\hline Norihisa et $\mathrm{al}^{21}$ & Retrospective & $\begin{array}{l}34 \text { lung mts } \\
\text { I5\% HNSCC }\end{array}$ & 48-60 Gy//2 Gy/4-8 days & $\begin{array}{l}\text { 2-year LRFR 90\% } \\
\text { 2-year PFSR 34.8\% } \\
\text { 2-year OS } 84.3 \%\end{array}$ \\
\hline Milano et $\mathrm{al}^{22}$ & Prospective & $\begin{array}{l}121 \text { lung mts } \\
19 \% \text { HNSCC }\end{array}$ & $50 \mathrm{~Gy} / 5 \mathrm{~Gy} / 2$ weeks & $\begin{array}{l}\text { 2-, 4-, 6-year LCR 74\%, 68\%, 65\% } \\
6 \text {-year OS } 47 \%\end{array}$ \\
\hline Rusthoven et $\mathrm{al}^{23}$ & Phase I/II & $\begin{array}{l}38 \text { lung mts } \\
7.9 \% \text { HNSCC }\end{array}$ & 48-60 Gy/l6-20 Gy/2 weeks & $\begin{array}{l}2 \text {-year LCR 96\% } \\
2 \text {-year OS 39\% }\end{array}$ \\
\hline Inoue et $\mathrm{al}^{24}$ & Retrospective & $\begin{array}{l}22 \text { lung mts } \\
9 \% \text { HNSCC }\end{array}$ & 40 Gy/l0 Gy/4-7 days & $\begin{array}{l}5 \text {-year LCR I00\% } \\
5 \text {-year OS } 72 \% \\
5 \text {-year PFSR } 54 \%\end{array}$ \\
\hline Takeda et $\mathrm{al}^{25}$ & Retrospective & $\begin{array}{l}34 \text { lung mts } \\
20 \% \text { HNSCC }\end{array}$ & $50 \mathrm{~Gy} / 10 \mathrm{~Gy} / 2$ weeks & 2-year LCR $82 \%$ \\
\hline
\end{tabular}

Abbreviations: HNSCC, head and neck squamous-cell carcinoma; LCR, local control rate; LRFR, locoregional free recurrence rate; mts, metastases; OS, overall survival; PFSR, progression-free-survival rate.

observed with liver metastasis. Katz et al reported the results of 174 liver metastases from different tumors. With a median of 15 months, local control was $76 \%$ and $57 \%$ at 10 and 20 months, respectively. No grade III toxicity was reported. ${ }^{26}$

Different prognostic factors have been studied in patients with SBRT-treated metastasis. Rusthoven et $\mathrm{a}^{23}$ showed a significant difference in 5-year survival for differently sized SBRT-treated metastases, with a 5-year local control rate of $100 \%$ for smaller lesions compared to $77 \%$ for those $>3 \mathrm{~cm}$. Other authors have shown a very low rate of 2 -year progression-free survival in cases with fewer than three metastases. ${ }^{27}$

There are some theoretical advantages to SBRT over surgery, with good immediate tolerance and ambulatory treatment, no need for anesthesia, and lower morbidity. ${ }^{28}$ Furthermore, SBRT has the potential to be combined with new systemic therapies, such as immunotherapy. It has been shown that hypofractionated RT with doses of $10 \mathrm{~Gy}$ or $20 \mathrm{~Gy}$ sensitize antigen tumors to T-cell-mediated rejection through loading of tumor stroma with tumor antigens, ${ }^{29}$ as well as enhanced functioning of effector T cells, inducing an abscopal effect at distance. ${ }^{30}$ Moreover, different preclinical studies have suggested that hypofractionated treatment with doses of $10 \mathrm{~Gy} \times 5$ fractions and 8 Gy $\times 3$ fractions plus CTLA4blocking antibodies induces a higher abscopal response than conventional fractionation. ${ }^{31,32}$ In addition, the combination of PDL1 inhibitors and SBRT has shown long survival in preclinical models. ${ }^{33}$ Finally, necrosis after ablative doses has been associated with liberation of more neoantigens, in contrast to the mitotic catastrophe induced by conventional fractionation. ${ }^{34}$ Different phase III studies are investigating the role of immunotherapy with CRT in HNC. The role of SBRT combined with immunotherapy in recurrent or $\mathrm{mHNC}$ cancer should be investigated. In summary, the treatment of metastasis with SBRT in oligometastatic disease is a safe procedure that offers the possibility of controlling the disease or delaying its progression, likewise delaying the need for further treatment.

\section{Patients with $\mathrm{HPV}^{+}$tumors with local or regional recurrence}

Some studies have suggested that locoregional control is an important prognostic factor for survival in patients with already established DM, ${ }^{35}$ supporting the concept that complete removal of the index primary tumor might be appropriate to achieve locoregional control, as long as this can be achieved with minimal morbidity.

Head and neck tumors associated with human papillomavirus (HPV) infections have been shown to follow a different natural course than $\mathrm{HPV}^{-}$ones. Huang et al ${ }^{36}$ compared the natural course of DM in $624 \mathrm{HPV}^{+}\left(\mathrm{p} 16^{+}\right)$and $\mathrm{HPV}^{-}\left(\mathrm{HPV}^{-} / \mathrm{p} 16^{-}\right)$patients for whom HPV status was available and who had metastatic oropharyngeal cancer treated with chemoradiotherapy (CRT). The authors found a higher proportion of disseminating phenotypes and multiple organs affected among $\mathrm{HPV}^{+}$patients compared to those who were $\mathrm{HPV}^{-}$, with DM as the predominant site of metastasis in these patients. Moreover, the subset of patients with $\mathrm{HPV}^{+}$tumors and oligometastatic disease presented prolonged survival times, even with palliative treatment. McBride et a ${ }^{37}$ investigated predictive factors for long-term survival in 25 patients with oropharyngeal cancer who developed metastases and had previously received radical approach treatment. Most of the patients $(84 \%)$ had DMs at the time of distant failure with a controlled primary tumor, and seven had limited disease (one or two adjacent lesions in a single organ). Fifteen patients 
(78.9\%) had undergone radical treatment for their DMs with surgery and/or RT, with or without systemic chemotherapy. HPV status was available for $54 \%$ of the patients, of whom $95 \%$ were $\mathrm{HPV}^{+}$. The authors reported a global rate of 2 -year OS of $40.8 \%$ after the development of metastases. Limited DM and Karnofsky PS (KPS) were independent prognostic factors for survival, showing a very favorable outcome in the low-risk patients (limited DM and KPS $\geq 80$ ), as $100 \%$ of the patients within this group survived $>2$ years after diagnosis of DM, whereas intermediate-risk (limited DM or KPS $\geq 80$ ) and high-risk patients (extensive disease and KPS <80) presented 2-year survival after metastasis of $45.8 \%$ and 0 , respectively. It should be noted that four of the five patients in the low-risk group were also $\mathrm{HPV}^{+}$. Finally, Sinha et $\mathrm{al}^{35}$ studied the clinical outcomes of 66 patients with metastasis from an oropharynx carcinoma, of whom $38 \%$ were $\mathrm{HPV}^{-}$and $62 \% \mathrm{HPV}^{+}$. Locoregional disease was present in $52 \%$ of the $\mathrm{HPV}^{-}$group compared with $25 \%$ in the $\mathrm{HPV}^{+}$patients $(P=0.022)$. A curative approach to the metastasis was performed in three $\mathrm{HPV}^{+}$patients $(12 \%)$ and eleven $\mathrm{HPV}^{-}$patients $(27 \%)$. However, all $\mathrm{p} 16^{-}$patients either suffered progression or died within 24 months of DM detection; 2-year post-DM progression-free survival in the p $16^{+}$patients was $20 \%$. Multivariate analysis identified that p16 negativity, no treatment/palliative treatment vs curative treatment of the metastasis, and presence of locoregional disease were associated with reduced post-DM disease-specific survival (Table 3 ).

\section{Patients with metastatic nasopharyngeal carcinoma and local or regional recurrence}

Recent research has investigated prognostic factors associated with long-term survival in patients with metastatic nasopharyngeal cancer ( $\mathrm{mNPC})$. A retrospective study of
263 patients diagnosed with mNPC identified two different prognostic groups of patients: patients with single-organ metastases or one to five lesions who presented a 5-year OS of $38.7 \%$ and patients with multiple-organ metastases or more than five lesions whose 5 -year OS was 7\%. In this study, treating the primary tumor with RT was a favorable prognostic factor for OS (HR 1.57, 95\% CI 1.10-2.25). ${ }^{38}$ In a recent study, Shen et $\mathrm{al}^{39}$ reported the results of a retrospective study of 312 patients with mNPC and bone-only metastases to identify which patients might benefit from combined CRT. In a multivariate analysis, the number of metastatic lesions (more than three vs three or fewer), spine involvement, and primary tumor-treatment modality (CRT vs chemotherapy or RT only) were independent prognostic factors for OS. Patients that were treated with CRT presented a 5-year OS of $57.3 \%$ compared with $11.2 \%$ in those that received palliative treatment with RT or chemotherapy. Cao et $\mathrm{al}^{40}$ analyzed 221 patients who developed single type DM after primary treatment. Multivariate analysis showed that age $>40$ years, local recurrence, disease-free interval $\leq 24$ months, and treatment with chemotherapy alone were independent negative prognostic factors. Moreover, CRT on the primary tumors was associated with longer survival in patients who presented up to two negative prognostic factors, with a median OS of 49.5 compared with 19.4 months.

Different clinical models are being investigated to better identify metastatic patients who may benefit from a curative approach. A recent report studied a prognostic classifier with support-vector-machine techniques to stratify $\mathrm{mNPC}$ in different prognostic groups. A ten-signature classifier was developed: three clinical variables (presence of oligometastases, N stage, and extraregional lymph-node metastasis) and seven hematological variables (Epstein-Barr virus viral capsid-antigen IgA, neutrophil count, monocyte count, platelet count, hemoglobin, glutamic-pyruvic

Table 3 Oligometastatic disease in NPC and $\mathrm{HPV}^{+}$tumors

\begin{tabular}{|c|c|c|c|c|}
\hline Study & Design & Patients & Treatment & Results \\
\hline Huang et $\mathrm{al}^{36}$ & Retrospective & 79 oropharynx, $\mathrm{HPV}^{+} 54$ vs HPV-25 & CRT of primary tumor & $\begin{array}{l}\text { 2-year OS } 11 \% \text { in } \mathrm{HPV}^{+} \text {vs } 4 \% \\
\text { in } \mathrm{HPV}^{-}\end{array}$ \\
\hline McBride et $\mathrm{al}^{37}$ & Retrospective & $\begin{array}{l}25 \text { oropharynx } \\
84 \% \text { primary controlled, } 95 \% \mathrm{HPV}^{+}\end{array}$ & Surgery or RT on metastases & $\begin{array}{l}\text { Limited DM and KPS }>80 \\
2 \text {-year OS } 100 \%\end{array}$ \\
\hline Sinha et $\mathrm{a}^{35}$ & Retrospective & 66 oropharynx, $62 \% \mathrm{HPV}^{+}$ & $\begin{array}{l}\text { Curative approach in } 12 \% \mathrm{HPV}^{+} \\
\text {and } 27 \% \mathrm{HPV}^{-}\end{array}$ & $\begin{array}{l}\text { 2-year PFS } 20 \% \text { in } \mathrm{HPV}^{+} \text {vs } 0 \\
\text { in } \mathrm{HPV}^{+}\end{array}$ \\
\hline Shen et $\mathrm{al}^{39}$ & Retrospective & 312 NPC, bone only & CRT vs palliative & $\begin{array}{l}5 \text {-year OS } 57.3 \% \text { in CRT vs } 11.2 \% \text { in } \\
\text { palliative treatment }\end{array}$ \\
\hline Cao et $\mathrm{al}^{40}$ & Retrospective & 22I NPC, single & CRT, CT & $\begin{array}{l}\text { 5-year OS } 49.5 \text { vs } 19.4 \text {, low- and } \\
\text { high-risk subsets }\end{array}$ \\
\hline
\end{tabular}

Abbreviations: CT, chemotherapy; CRT, chemoradiotherapy; DM, distant metastasis; HPV, human papillomavirus; NPC, nasopharyngeal cancer; OS, overall survival; PFS, progression-free survival. 
transaminase, and glutamyl transpeptidase). Patients classified as low risk presented different survival after treatment of the primary tumor with CRT compared with chemotherapy alone, with 5 -year OS of $47 \%$ and $10 \%$, respectively $(P>0.001) .{ }^{41}$ Investigation is needed to select precisely which patients with mNPC may benefit from a more radical approach.

\section{Future perspectives}

One of the key issues in the treatment of oligometastatic disease is how to identify accurately which tumors have true oligometastatic disease and which patients will benefit from a radical approach. Clinical factors have been shown to be ineffective for accurate prediction of which patients are at the oligometastatic stage and may be candidates for a radical approach. Different molecular approaches are being tested to correlate biological markers with clinical outcomes and improve the ability to predict oligometastatic disease. Lussier et $\mathrm{al}^{42}$ analyzed miRNA expression from lung metastases in patients with fewer than five metastases treated with curative intent. Stratification with miRNA expression identified two groups of patients with different rates of progression and survival. Further, the existence of circulating tumor cells has been shown to be predictive of response to systemic therapy in metastatic breast cancer. ${ }^{43}$ Theoretically, circulating tumor cells may help to identify patients with a true oligometastatic state that will facilitate accurate selection of patients for a radical approach, ${ }^{44}$ increasing the therapeutic ratio of patients.

Finally, recent data from immunotherapy trials performed on recurrent and $\mathrm{mHNC}$ patients have suggested that a subgroup of patients may present a considerable increase in longterm survival after treatment with checkpoint inhibitors. ${ }^{3}$ The role of radical treatment with $\mathrm{RT}$ in this clinical setting should be studied in future.

\section{Conclusion}

Despite limited evidence, due to the retrospective nature of the data, some conclusions can be drawn. In mHNC, although chemotherapy is considered the standard treatment, RT offers a high chance of palliation. In metastatic patients with a good PS, a high-dose regimen could be used after careful patient selection. In oligometastatic disease, some clinical settings should be considered for a more curative approach. In patients with a controlled primary tumor that present favorable prognostic factors, such as a high KPS $(\geq 80)$ and a limited number of metastases, a radical approach with SBRT should be considered. In the presence of locoregional recurrence, it is unknown whether treatment over the primary tumor is indicated. However, particularly in $\mathrm{HPV}^{+}$patients, after a consideration of prognostic factors, local treatment with RT might be appropriate. Not enough data are available to recommend this approach for $\mathrm{HPV}^{-}$patients. Those with NPC with a limited number of metastases, particularly those with bone metastases, might be candidates for a radical approach to metastasis with SBRT. Retrospective data indicate that in mNPC patients with primary tumor recurrence and a limited number of metastases, treatment of the primary tumor with RT might be also indicated. Prospective studies are needed to identify which metastatic patients may benefit from a radical approach with RT.

\section{Disclosure}

The authors report no conflicts of interest in this work.

\section{References}

1. Sacco AG, Cohen EE. Current treatment options for recurrent or metastatic head and neck squamous cell carcinoma. J Clin Oncol. 2015; 33(29):3305-3313

2. Ferlito A, Shaha AR, Silver CE, Rinaldo A, Mondin V. Incidence and sites of distant metastases from head and neck cancer. ORL. 2001;63(4): 202-207.

3. Vermorken JB, Mesia R, Rivera F, et al. Platinum-based chemotherapy plus cetuximab in head and neck cancer. N Engl J Med. 2008;359(11): 1116-1127.

4. Porceddu SV, Rosser B, Burmeister BH, et al. Hypofractionated radiotherapy for the palliation of advanced head and neck cancer in patients unsuitable for curative treatment - "Hypo Trial". Radiother Oncol. 2007:85:456-462. Available from: http://www.sciencedirect. com/science/article/pii/S0167814007005300

5. Margalit DN, Schoenfeld JD, Tishler RB. Radiation Oncology - New Approaches in Squamous Cell Cancer of the Head and Neck. Hematol Oncol Clin North Am. 2015;29(6):1093-1106.

6. Mohanti BK, Umapathy H, Bahadur S, Thakar A, Pathy S. Short course palliative radiotherapy of $20 \mathrm{~Gy}$ in 5 fractions for advanced and incurable head and neck cancer: AIIMS study. Radiother Oncol. 2004; 71(3):275-280.

7. Fortin B, Khaouam N, Filion E, Nguyen-Tan PF, Bujold A, Lambert L. Palliative radiation therapy for advanced head and neck carcinomas: A phase 2 study. Int J Radiat Oncol Biol Phys. 2016;95(2):647-653.

8. Stevens CM, Huang SH, Fung S, et al. Retrospective study of palliative radiotherapy in newly diagnosed head and neck carcinoma. Int J Radiat Oncol Biol Phys. 2011;81(4):958-963.

9. Corry J, Peters LJ, Costa ID, et al. The 'QUAD SHOT' - a phase II study of palliative radiotherapy for incurable head and neck cancer. Radiother Oncol. 2005;77(2):137-142.

10. Agarwal JP, Nemade B, Murthy V, et al. Hypofractionated, palliative radiotherapy for advanced head and neck cancer. Radiother Oncol. 2008;89(1):51-56.

11. Hellman S, Weichselbaum RR. Oligometastases. J Clin Oncol. 1995; 13(1):8-10.

12. Weichselbaum RR, Hellman S. Oligometastases revisited. Nat Rev Clin Oncol. 2011;8(6):378-382.

13. Young ER, Diakos E, Khalid-Raja M, Mehanna H. Resection of subsequent pulmonary metastases from treated head and neck squamous cell carcinoma: systematic review and meta-analysis. Clin Otolaryngol. 2015;40(3):208-218.

14. Liu D, Labow DM, Dang N, et al. Pulmonary metastasectomy for head and neck cancers. Ann Surg Oncol. 1999;6(6):572-578. 
15. Shiono S, Kawamura M, Sato T, et al. Pulmonary metastasectomy for pulmonary metastases of head and neck squamous cell carcinomas. Ann Thorac Surg. 2009;88(3):856-860.

16. Nibu K, Nakagawa K, Kamata S, et al. Surgical treatment for pulmonary metastases of squamous cell carcinoma of the head and neck. Am J Otolaryngol. 1997;18(6):391-395.

17. Finley RK, Verazin GT, Driscoll DL, et al. Results of surgical resection of pulmonary metastases of squamous cell carcinoma of the head and neck. Am J Surg. 1992;164(6):594-598.

18. Potters L, Kavanagh B, Galvin JM, et al. American Society for Therapeutic Radiology and Oncology (ASTRO) and American College of Radiology (ACR) practice guideline for the performance of stereotactic body radiation therapy. Int J Radiat Oncol Biol Phys. 2010;76(2): 326-332.

19. Willers H, Held KD. Introduction to clinical radiation biology. Hematol Oncol Clin North Am. 2006;20(1):1-24.

20. Timmerman RD. An overview of hypofractionation and introduction to this issue of seminars in radiation oncology. Semin Radiat Oncol. 2008;18(4):215-222.

21. Norihisa Y, Nagata Y, Takayama K, et al. Stereotactic body radiotherapy for oligometastatic lung tumors. Int J Radiat Oncol Biol Phys. 2008;72(2):398-403

22. Milano MT, Philip A, Okunieff P. Analysis of patients with oligometastases undergoing two or more curative-intent stereotactic radiotherapy courses. Int J Radiat Oncol Biol Phys. 2009;73(3):832-837.

23. Rusthoven KE, Kavanagh BD, Burri SH, et al. Multi-institutional phase I/II trial of stereotactic body radiation therapy for lung metastases. J Clin Oncol. 2009;27(10):1579-1584.

24. Inoue T, Katoh N, Onimaru R, Shirato H. Clinical outcomes of stereotactic body radiotherapy for patients with lung tumors in the state of oligo-recurrence. Pulm Med. 2012;2012:1-5.

25. Takeda A, Kunieda E, Ohashi T, Aoki Y, Koike N, Takeda T. Stereotactic body radiotherapy (SBRT) for oligometastatic lung tumors from colorectal cancer and other primary cancers in comparison with primary lung cancer. Radiother Oncol. 2011;101(2):255-259. http://www.ncbi. nlm.nih.gov/pubmed/21641064

26. Katz AW, Carey-Sampson M, Muhs AG, Milano MT, Schell MC, Okunieff $\mathrm{P}$. Hypofractionated stereotactic body radiation therapy (SBRT) for limited hepatic metastases. Int J Radiat Oncol Biol Phys. 2007;67(3):793-798.

27. Salama JK, Hasselle MD, Chmura SJ, et al. Stereotactic body radiotherapy for multisite extracranial oligometastases: final report of a dose escalation trial in patients with 1 to 5 sites of metastatic disease. Cancer. 2012;118(11):2962-2970.

28. Florescu C, Thariat J. Local ablative treatments of oligometastases from head and neck carcinomas. Crit Rev Oncol Hematol. 2014;91(1):47-63.

29. Zhang B, Bowerman NA, Salama JK, et al. Induced sensitization of tumor stroma leads to eradication of established cancer by T cells. J Exp Med. 2007;204(1):49-55.
30. Burnette B, Weichselbaum RR. The immunology of ablative radiation. Semin Radiat Oncol. 2015;25(1):40-45.

31. Camphausen K, Moses MA, Ménard C, et al. Radiation abscopal antitumor effect is mediated through p53. Cancer Res. 2003;63(8):1990-1993.

32. Dewan MZ, Galloway AE, Kawashima N, et al. Fractionated but not single-dose radiotherapy induces an immune-mediated abscopal effect when combined with anti-CTLA-4 antibody. Clin Cancer Res. 2009;15(17):5379-5388.

33. Zeng J, See AP, Phallen J, et al. Anti-PD-1 blockade and stereotactic radiation produce long-term survival in mice with intracranial gliomas. Int J Radiat Oncol Biol Phys. 2013;86(2):343-349.

34. Lauber K, Ernst A, Orth M, Herrmann M, Belka C. Dying cell clearance and its impact on the outcome of tumor radiotherapy. Front Oncol. 2012;2:116.

35. Sinha P, Thorstad WT, Nussenbaum B, et al. Distant metastasis in p16-positive oropharyngeal squamous cell carcinoma: a critical analysis of patterns and outcomes. Oral Oncol. 2014;50(1):45-51.

36. Huang SH, Perez-Ordonez B, Weinreb I, et al. Natural course of distant metastases following radiotherapy or chemoradiotherapy in HPV-related oropharyngeal cancer. Oral Oncol. 2013;49(1):79-85.

37. McBride SM, Busse PM, Clark JR, Wirth LJ, Ancukiewicz M, Chan AW. Long-term survival after distant metastasis in patients with oropharyngeal cancer. Oral Oncol. 2014;50(3):208-212.

38. Zeng L, Tian YM, Huang Y, et al. Retrospective analysis of 234 nasopharyngeal carcinoma patients with distant metastasis at initial diagnosis: therapeutic approaches and prognostic factors. PLoS One. 2014;9(9):e108070. http://dx.plos.org

39. Shen L, Li W, Wang S, et al. Image-based Multilevel Subdivision of M1 Category in TNM Staging System for Metastatic Nasopharyngeal Carcinoma. Radiology. 2016;280(3):805-814. http://pubs.rsna.org/doi

40. Cao X, Han Y, He L, Xiang J, Wen Z. Risk subset of the survival for nasopharyngeal carcinoma patients with bone metastases: who will benefit from combined treatment? Oral Oncol. 2011;47(8):747-752.

41. Jiang R, You R, Pei XQ, et al. Development of a ten-signature classifier using a support vector machine integrated approach to subdivide the M1 stage into M1a and M1b stages of nasopharyngeal carcinoma with synchronous metastases to better predict patients' survival. Oncotarget. 2016;7(3):3645-3657.

42. Lussier YA, Khodarev NN, Regan K, et al. Oligo- and polymetastatic progression in lung metastasis(es) patients is associated with specific microRNAs. PLoS One. 2012;7(12):e50141.

43. Cristofanilli M, Budd GT, Ellis MJ, et al. Circulating tumor cells, disease progression, and survival in metastatic breast cancer. $N$ Engl $J$ Med. 2004;351(8):781-791.

44. Ricardi U, Badellino S, Filippi AR. Clinical applications of stereotactic radiation therapy for oligometastatic cancer patients: a disease-oriented approach. J Radiat Res. 2016;57:i58-i68.
OncoTargets and Therapy

\section{Publish your work in this journal}

OncoTargets and Therapy is an international, peer-reviewed, open access journal focusing on the pathological basis of all cancers, potential targets for therapy and treatment protocols employed to improve the management of cancer patients. The journal also focuses on the impact of management programs and new therapeutic agents and protocols on

\section{Dovepress}

patient perspectives such as quality of life, adherence and satisfaction. The manuscript management system is completely online and includes a very quick and fair peer-review system, which is all easy to use. Visit http://www.dovepress.com/testimonials.php to read real quotes from published authors. 